Jurnal Keperawatan Silampari

Volume 2, Nomor 2, Juni 2019

e-ISSN: 2581-1975

p-ISSN: 2597-7482

DOI: https://doi.org/10.31539/jks.v2i2.531

\title{
PENGALAMAN PASIEN DIABETES MELITUS TIPE 2 DALAM MELAKUKAN TINDAKAN PENCEGAHAN TERJADINYA LUKA PADA KAKI
}

\author{
Nur Afni Wulandari ${ }^{1}$, Agung Waluyo ${ }^{2}$, Diana Irawati ${ }^{3}$ \\ Program Studi Ners, STIKES Kesetiakawanan Sosial Indonesia ${ }^{1}$ \\ Program Studi Ners, Universitas Indonesia ${ }^{2}$ \\ Program Studi Magister Keperawatan, Universitas Muhammadiyah Jakarta ${ }^{3}$ \\ nurafni.w@yahoo.com ${ }^{1}$
}

\begin{abstract}
ABSTRAK
Penelitian ini bertujuan untuk mendapatkan pemahaman yang mendalam tentang arti dan makna dari pengalaman pasien diabetes melitus tipe 2 dalam melakukan tindakan pencegahan terjadinya luka di PERSADIA Rumah Sakit Islam Jakarta Pondok Kopi. Penelitian ini menggunakan desain kualitatif dan pengambilan data dilakukan dengan teknik wawancara secara mendalam. Hasil yang diperoleh terdapat 4 empat) tema yang dihasilkan, yaitu gambaran menjaga diit, aktivitas kontrol gula darah yang beragam, tantangan kepatuhan terapi dan kemampuan merawat kaki yang benar. Simpulan, pengalaman pasien diabetes melitus tipe 2 dalam mencegah terjadinya luka, sebaiknya patuh terhadap pengobatan dan menjaga makanan sesuai diit sehingga kadar gula darah tetap stabil. Hal lain yang perlu diperhatikan adalah, peran aktif petugas kesehatan dalam memberikan edukasi mengenai perawatan kaki yang benar.
\end{abstract}

Kata kunci: Diabetes Melitus Tipe 2, Pencegahan Terjadinya Luka

\section{ABSTRACT}

This study aims to gain an in-depth understanding of the meaning and significance of the experience of type 2 diabetes mellitus patients in taking preventive measures for injury at PERSADIA Islamic Hospital Jakarta Pondok Kopi. This study uses a qualitative design and data collection is done by in-depth interview techniques. The results obtained were four) themes produced, namely the picture of maintaining diet, diverse blood sugar control activities, the challenges of therapeutic adherence and the ability to properly care for the feet. Conclusion, the experience of type 2 diabetes mellitus patients in preventing injuries, should adhere to the treatment and maintain the food according to diet so that blood sugar levels remain stable. Another thing to note is, the active role of health workers in providing education about proper foot care.

Keywords: Type 2 Diabetes Mellitus, Prevention of Wound Occurrence 


\section{PENDAHULUAN}

Sistem endokrin mengendalikan proses tubuh melalui zat kimia, sebagian besar zat kimia ini disekresi didalam kelenjar. Kelenjar endokrin terletak di seluruh tubuh dan masing-masing kelenjar mengandung sekelompok sel khusus yang menyekresi hormon langsung kedalam aliran darah, di edarkan ke seluruh tubuh. Hormon ini bekerja pada jaringan yang jauh (disebut jaringan target) melalui sinyal endokrin (Rosdhal, Kowalski, 2014).

Sel pankreas menghasilkan sebuah hormon yang disebut insulin untuk mengatur metabolisme, tanpa hormon ini glukosa tidak dapat masuk sel tubuh dan kadar glukosa darah meningkat. Penurunan jumlah, pengurangan, atau tidak efektifnya penggunaan insulin memicu gangguan diabetes mellitus (Roshdal, Kowalski, 2014). Diabetes Melitus adalah penyakit kronis yang kompleks yang membutuhkan perawatan medis berkelanjutan dengan strategi pengurangan risiko multi faktor di luar kontrol glikemik. Pasien yang mendapat pendidikan dan dukungan manajemen mandiri terus menerus sangat penting untuk mencegah komplikasi akut dan mengurangi risiko komplikasi jangka panjang (ADA, 2016). Menurut IDF (2015) Diabetes adalah kondisi kronis yang terjadi ketika tubuh tidak bisa menghasilkan insulin yang cukup atau tidak dapat menggunakan insulin, dan didiagnosis mengalami peningkatan kadar glukosa dalam darah. Insulin adalah hormon diproduksi di pankreas, diperlukan untuk mengangkut glukosa dari aliran darah ke sel-sel tubuh digunakan sebagai energi. Kekurangan, atau ketidakefektifan, insulin pada seseorang dengan diabetes berarti glukosa itu tetap beredar di dalam darah. Seiring waktu, hasilnya kadar glukosa yang tinggi dalam darah (dikenal sebagai hiperglikemia) menyebabkan kerusakan banyak jaringan di dalam tubuh, yang menyebabkan perkembangan komplikasi kesehatan yang mematikan dan mengancam jiwa.

Diabetes Melitus merupakan salah satu penyakit kronis yang tidak ditularkan dari orang ke orang (PTM). Penyakit Kronis Tidak Menular diantaranya adalah asma, penyakit paru obstruksi kronis (PPOK), kanker, hipertiroid, hipertensi, jantung koroner, gagal jantung, stroke, gagal ginjal kronis, batu ginjal, dan penyakit sendi/rematik. Menurut World Health Organiation (WHO) jumlah penderita Diabetes Melitus pada tahun 2015 tercatat 415 juta orang dan diperkirakan pada tahun 2040 jumlah penderita DM akan menjadi 642 juta orang. Hampir 80\% penyandang diabetes ada di Negara berpenghasilan rendah dan menengah (WHO, 2015). Di Asia Tenggara pada tahun 2014 terdapat 96 juta orang dewasa dengan diabetes melitus. Populasi dari wilayah regional Asia Tenggara secara genetik memang rentan terhadap faktor diabetogenik lingkungan, sehingga memiliki ambang lebih rendah terhadap faktor resiko seperti usia, kelebihan berat badan, dan distribusi lemak tubuh. Di wilayah regional Asia Tenggara, diabetes melitus terjadi 10 tahun lebih cepat dibandingkan dengan orang-orang di wilayah Eropa, pada usia dimana masa paling produktif (WHO, 2015).

Pravalensi penderita Diabetes tertinggi terjadi di Daerah Istimewa Yogyakarta sebanyak 2,6 \%, sementara DKI Jakarta menempati urutan kedua yaitu sebanyak 2,5\% dan jumlah penderita DM yang paling rendah terdapat di propinsi Lampung sebanyak 0,7\% (Riskesdas, 2015). Beberapa klasifikasi Diabetes Melitus menurut World Health Organizations (WHO) dibagi menjadi empat antara lain; Diabetes Melitus tipe 1, Diabetes Melitus tipe 2, Diabetes Gestasional dan Diabetes tipe lain. Faktor utama perkembangan DM tipe 2 adalah resistensi selular terhadap efek insulin. Resistensi ini ditingkatkan oleh 
kegemukan, tidak beraktivitas, penyakit, obat-obatan, dan pertambahan usia. Pada kegemukan, insulin mengalami penurunan kemampuan untuk memengaruhi absorpsi dan metabolisme glukosa oleh hati, otot rangka dan jaringan adiposa (Lemone, 2016). Metabolisme glukosa yang abnormal memiliki efek patologis yang serius pada hampir seluruh sistem tubuh. Komplikasi Diabetes yang paling penting adalah abnormalitas pembuluh darah, kerusakan ginjal dan lesi yang menegenai saraf perifer dan mata (Kumar, 2015).

Salah satu komplikasi umum dari Diabetes adalah masalah kaki diabetes, kaki diabetes yang tidak dirawat dengan baik akan mudah mengalamai luka, dan cepat berkembang menjadi ulkus gangren bila tidak dirawat dengan benar (Soegondo, 2015). Luka diabetik adalah luka yang terjadi pada pasien dengan diabetik yang melibatkan gangguan pada saraf periferal dan autonomik. Penyebabnya adalah karena neuropati (kerusakan saraf) dan periferal vaskular disease (Suriadi, 2004). Data dari Rumah Luka Indonesia menunjukan bahwa $60 \%$ penderita mengalami gangguan pada saraf (neuropati) dan $60 \%$ memiliki resiko luka pada kaki. Luka DM juga merupakan penyebab amputasi pada kaki dengan porsentase 40-70\% (Rumah Luka Indonesia, 2013 dalam Maghfuri, 2016). Diperkirakan bahwa 50-75\% dari amputasi tersebut sebenarnya dapat dicegah, tetapi penatalaksanaan jangka panjang pada pasien Diabetes dan pencegahan terhadap komplikasinya masih merupakan suatu tantangan. Hal tersebut memerlukan pendekatan tim multidisiplin yang terkoordinasi, yang melibatkan dokter, perawat spesialis diabetes, siropordis, dan orthotist serta pada beberapa kasus memerlukan ahli bedah vaskuler dan ahli bedah ortopedi tetapi semua memerlukan kerjasama pasien yang telah mendapatkan informasi (Moya, 2004).

Perawatan kaki pada pasien diabetes melitus penting dilakukan karena seseorang dengan diabetes melitus beresiko untuk masalah kaki dan kuku akibat suplay darah perifer yang kurang baik ke kaki, sensasi proeksi di kaki juga berkurang sehingga trauma pada kaki sering kali tidak diketahui dan adanya kerusakan kulit maka infeksi akan lebih mudah berkembang karena sirkulasi yang buruk. Perawatan kaki dan kuku perlu dilakukan secara rutin untuk mencegah infeksi, bau kaki, dan cidera jaringan lunak. Pasien harus patuh dalam melakukan perawatan kaki untuk mengurangi resiko terjadinya ulkus pada kaki (Potter, Perry, 2005). Salah satu penelitian pada tahun 2012 yang telah dilakukan di PKU Muhammadiyah Jogjakarta oleh Arianti yaitu hubungan antara perawatan kaki dengan resiko ulkus kaki diabetes, hasil yang didapatkan bahwa perawatan kaki mandiri serta pemilihan dan pemakaian alas kaki yang benar dapat mencegah resiko terjadinya ulkus (Arianti, 2012).

Ada lima komponen dalam penatalaksanaan diabetes tipe 2, yaitu terapi nutrisi (diet), latihan fisik, pemantauan, terapi farmakologi dan pendidikan (Smeltzer, 2008). Banyak masalah kaki dapat dicegah atau dipecahkan pada tahap dini dengan cara memberikan edukasi khusus tentang sirkulasi, pemeriksaan sendiri, perlindungan dan perawatan kaki harian (Black, Hawks, 2014).

Adanya komplikasi berupa ulkus maupun gangren akan mempengaruhi dan membawa dampak di kehidupan individu dan keluarga. Dampak masalah yang terjadi pada individu diantaranya perubahan pada pola persepsi dan tata laksana hidup sehat, perubahan pola nutrisi dan metabolisme, perubahan pola eliminasi, perubahan pola tidur dan istrahat, perubahan pola aktivitas dan latihan, perubahan pola hubungan dan peran, perubahan pola 
sensori dan kognitif, perubahan pola persepsi dan konsep diri, perubahan pola seksual dan reproduksi, perubahan pola stress dan koping, serta perubahan pada tata nilai dan kepercayaan (Maghfuri, 2016). Oleh karena itu studi fenomenologi tentang pengalaman pasien diabetes melitus tipe 2 dalam melakukan tindakan pencegahan terjadinya luka pada kaki, penting untuk dilakukan agar bisa mengeksplor lebih jauh dan lebih mendalam mengenai pengalaman para partisipan dalam upaya mengendalikan atau menstabilkan kadar gula darah dalam mencegah komplikasi DM seperti luka kaki maupun ulkus gangren. Metode penelitian kualitatif memungkinkan penelitian mampu menggambarkan dan menginterpretasikan perilaku manusia tersebut berdasarkan pengalaman subjektif dalam bentuk narasi atau cerita langsung dari fenomena atau situasi yang dialami manusia sebagai subjek yang diteliti.

\section{METODE PENELITIAN}

Jenis penelitian yang digunakan adalah penelitian kualitatif dengan pendekatan fenomenologi. Fenomena yang diteliti adalah pengalaman pasien diabetes mellitus Tipe 2 dalam melakukan tindakan pencegahan terjadinya luka pada kaki di Persadia Rs. Islam Jakarta Pondok Kopi. Instrumen dalam penelitian ini adalah peneliti sendiri. Validasi penelitian dilakukan dengan wawancara secara mendalam dengan informan yang sesuai dengan kriteria penelitian. Alat penelitian lain yang digunakan adalah alat tulis, mp 4 player, Hp dan pedoman wawancara.

Populasi ada penelitian ini adalah para pasien diabetes mellitus tipe 2 yang memenuhi kriteria insklusi yaitu: Mampu berkomunikasi dengan jelas. Kriteria ini penting karena menilai kemampuan partisipan dalam berkomunikasi dengan baik itu akan memudahkan peneliti memahami maksud yang disampaikan oleh partisipan, Partisipan yang menjalani perawatan dirumah dengan alasan bahwa partisipan yang menjalani perawatan dirumah akan secara aktif terlibat dalam manajemen diabetes mandiri yaitu manajemen diet, aktivitas fisik/olahraga, pengontrolan kadar gula darah, terapi farmakologi dan perawatan kaki secara mandiri sebagai upaya pencegahan terjadinya luka. Pengalaman inilah yang menjadi fokus dari penelitian.Bersedia ikut sebagai partisipan dengan menandatangani surat kesediaan sebagai partisipan. Sampel dalam penelitian ini diambil dengan menggunakan teknik purposive sampling yaitu memilih beberapa informan sesuai dengan kriteria-kriteria. Setelah dilaksanakannya penelitian, didapat delapan informan sangat berpartisipasi dalam penelitian ini.

Pengambilan data pada informan dilaksanakan dengan menggunakan teknik wawancara terstruktur dan mendalam (in-depth interview) dan dibantu dengan penggunaan pedoman wawancara semi struktur yang berisi pertanyaan terbuka terkait tujuan penelitian yang akan dicapai. Wawancara dilakukan sekitar 45-60 menit sesuai dengan tempat dan waktu yang telah disepakati bersama informan sebelumnya. Selanjutnya Informan bersedia menandatangani lembar persetujuan untuk berpartisipasi dalam penelitian ini. Setelah terkumpul data, Data dianalisis dengan menggunakan metode Collaizi yaitu suatu metode yang digunakan oleh peneliti yang melibatkan hasil observasi dan analisis perilaku individu dalam kesehariannya untuk menguji hasil pengalaman yang tidak bisa diungkapkan dengan kata-kata atau secara verbal. Hasil wawancara direkam langsung dengan menggunakan mp4 player. Validasi data langsung dilakukan oleh peneliti bila ada yang informasi yang kurang jelas dari jawaban masing-masing informan. Pengambilan gambar juga dilakukan oleh 
peneliti untuk pendokumentasian yang dilakukan dengan menggunakan HP dan pengambilan data dihentikan apabila sudah tidak ada lagi data baru yang didapat atau data telah mencapai saturasi.

\section{HASIL PENELITIAN}

Informan dalam penelitian ini berjumlah delapan (delapan) orang pasien diabetes mellitus tipe 2, dan yang menjalani perawatan dirumah.

Peneliti melakukan proses analisis data dengan menggunakan metode Collaizi dari data yang dihasilkan oleh peneliti dari hasil catatan lapangan dan selanjutnya peneliti memberikan kode agar sumber datanya mudah ditelusuri. Dalam mengumpulkan dan membuat kata kunci peneliti berupaya menemukan tema-tema yang berasal dari data, kemudian peneliti mengkoding data tersebut.

Dari hasil temuan lapangan oleh peneliti, telah mengidentifikasi ada 4 (empat) tema yang dihasilkan. kategori tema tersebut terdaftar sebagai berikut :

Tabel.1

Kategori dan Tema

\begin{tabular}{cllll}
\hline No & \multicolumn{1}{c}{ Kategori } & Tema & \\
1 & $\begin{array}{l}\text { Gambaran pengetahuan pasien diabetes mellitus tipe } \\
\text { 2 dalam hal nutrisi }\end{array}$ & Menjaga Diit & & \\
2 & $\begin{array}{l}\text { Karakteristik partisipan dalam melakukan kontrol } \\
\text { gula darah }\end{array}$ & $\begin{array}{l}\text { Aktivitas kontrol gula darah yang } \\
\text { beragam }\end{array}$ \\
3 & Mencegah terjadinya luka dengan terapi pengobatan & Tantangan kepatuhan terapi \\
4 & Gambaran pengetahuan merawat kaki & Kemampuan merawat kaki yang benar \\
\hline
\end{tabular}

\section{Adapun 4 tema yang didapat adalah : 1) Menjaga Diit}

“....Makanan itu setiap hari harus kita jaga. Udah ada ukurannya sih sebenarnya mbak.Nih ya kayak karbohidratnya harus kita timbang, terus buah-buahan juga di timbang, kata dokter gitu mbak,,, "(P1)

".....Sekarang mah ibukudu jaga makan, gk bisa makan nasi putih makannya beras merah dicampur dengan beras putih.Jadi takarannya itu lebih banyak beras merah. Sebenarnya mah kurang suka ibu sama beras merah teh, tapi kumaha namanya sakit ya,,, "(P2)

“........Saran dari dokter kalau bisa makannya diganti aja beras merah karena menggandung low glikemik, walaupun rasanya saya kurang suka karena beda dengan nasi biasa ... apa-apa kalau mau makan bapak ikuti saran dokter, sesuai aturannya harus dijaga ajalah.." (P3)

“.......Makannya diatur, tetap sih $3 x$ sehari tapi porsinya di kurangi ukurannya, terus makan buah-buahan dan kalau ibu bikin teh gulanya diganti jadi gula tropika,,,.” (P4)

“......Semenjak kena diabetes ya sus, kalau ibu makan cuman 2 centong untuk sekali makan, tapi makannya tetap 3x sehari. Ibu usahakan jaga betul makanan ibu,," (P5)

“....Kata dokter harus makan buah-buahan, makan sayuran tapi jangan berlebihan, jangan makan kulit ayam, jangan makan daging. Kalau mau makan itu harus buah-buahan dulu, terus sayuran, baru deh nanti makan nasi sama lauknya. Nasinya dikiiit aja, sayur tuh sama lauknya banyakin.....” (P6) 
“.......Makan 3x kali sehari sekali makan itu secentong, kalau minum teh gulanya diganti tropika.Kadang bapak juga kegoda mau nambah nasi, tapi kalau ingat sakit ya gimana dong? Itu yang bapakjaga, mau nggak mau dikit aja makannya,,,, ", (P7)

“....Pola makannya tetap 3x sehari aja sih nggak ada perubahan. Porsi nasinya dikurangi, terus banyakin makan sayuran.....” (P8)

Saturasi data : dari delapan partisipan, semuamenjawabupaya yang dilakukan untuk mencegah terjadinya luka pada kaki adalah dengan menjaga diit sesuai aturan.

\section{Aktivitas Kontrol Gula Darah yang Beragam}

“....Pengalaman ya, ibu ngecegahnya hmmm dengan rutin kontrol gula. Selama kontrol gula darah nggak susah sih karena kan di rumah saya juga sudah ada alatnya sendiri, jadi kalau misalkan mau ngecek bisa dilakukan sendiri, ,," (P1)

“....Ibu udah hampir 7 tahun kena gula, belum pernah sampai luka dan mudah-mudahan jangan sampai yaaa. Kata orang ibu ini gula kering, jadi yaaa gitu mungkin kontrol darah ke rumah sakit setiap sebulan sekali, tapi kadang seminggu sekali kontrol darahnya ke rumah teman yang punya alat karena alatnya ibu udah rusak...” (P2)

“........Ini loh dek, biar nggak luka bapak semenjak tahu kena diabetes melitus, bapak rutin ngecek-ngecek ke rumah sakit sebulan sekali, kalau di luar rumah sakit nggak pernah.Sebisa mungkin nggak lupa sih untuk cek gulanya. Bukan apanya, kalau ngecek diluar bapak kurang percaya aja gitu sama hasilnya nggak tau deh kenapa. Nantikan kita juga dapat saran apaaa gitu dari dokter, lah kan enak....” (P3)

“.....Apa yaaaa, kalo ibu biar nggak sampai luka juga? Ibu biasanya kontrol gula.Untuk kontrol gulanya saya rutin kontrol di rumah sakit, kalau di luar rumah sakit nggak pernah karena saya kurang yakin,, "(P4)

“........Alhamdulillah sampai sekarang belum pernah ibu mah ada luka-luka di kaki neng, apa karena rutin ngecek gula ya? soalnya ibu ngecek sendiri gulanya. Nah kebetulan ibu punya alatnya sendiri di rumah, jadi biasa anak ibu yang ngecek gulanya ibu...." (P5)

“......Semenjak tau gula ibu tinggi, hmmm ibu rutin kontrol ke tempat yang ada untuk cekcek gula.Ibu takut iiihh kalau sampai ada lukanya, kayak tetangga ibu tuh ada yang gituu.Ya terserah mau seminggu sekali kek, apa sebulan berapa kali yang jelas di cek pokoknya dah. Sambilan juga makanan di jaga, kan percuma ye rajin ngecek tapi makan semua di embat!!...” (P6)

“.......Begini dek, namanya juga sakit nggak ada yang enak. Tapi kita tetap harus ada usaha juga tuh, ya macam biar ndak luka itu tuh, bapak usahakan rutin kontrol gula juga...."(P7)

“......Kalau kata dokter biar nggak jd komplikasi macam apa sih namanya hmmm... lukaluka yang di kaki, harus jaga gulanya jangan sampe naek. Saya biasa ngecek ke puskesmas aja yang agak deket dari rumah....." (P8) 
Saturasi data: dari delapan partisipan menjawab semua menjawab bahwa rutin melakukan kontrol gula darah untuk mencegah terjadinya luka. Kontrol gula darahnya beragam, ada yang melakukan secara mandiri, di puskesmas maupun rumah sakit.

\section{Tantangan Kepatuhan Terapi}

“.........Kadang-kadang kalau lagi males ya nggak minum karena minum tidak minum obat perasaan ibu kayak sama aja sih nggak ada bedanya. Apa mngkin cuman perasaan ibu aja ya yang kayak gitu, yang kadang males lah buat minum obat. Itu juga insulin kan harganya lumayan mahal, jadi kerasa berat di biaya tapi kalau nggk gitu ibu takut kenapa-kenapa entar,," (P1)

“.....Kalau bisa ibu nggak usah minum obat karena bosan juga, ibu mah sukanya minum jamu godogan gitu.Semoga aja atuh setelah minum jamu-jamu gitu kaki ibu sehat-sehat ya neng gk luka. Karena pengalaman ibu selama ini ya sambilan minum jamu juga.,," (P2)

“......Sekarang ini saya minum obat tradisional aja untuk jaga-jaga jangan sampai kaki saya kenapa-kenapa, kalau di Jawa itu ada namanya daun papaya yang pahit, jadi daundaun aja.Masalahnya gini loh dek, saya kalau minum obat-obat yang dokter itu badan saya nggak cocok dengan obat-obatan itu. Langsung kayak apa sih, kayak alergi gitu loh.,,,",(P3)

“....... Selama ibu ada gulanya, ibu disuruh sama dokter perhatiin obatnya. Tapi yaa namanya udah ibu-ibu ya sus, suka lupa sama minum obat!! Karena dokter bilang yang namanya penyakit gula itu sudah di kontrak seumur hidup buat minum obat, capek juga sih hmmmm ,,, (P4)

“....... Cara ibu pribadi yah dek biar gk luka di kaki ya rutin minum obat, tapi saking gimana sih ya, eeemm saking seringnya kali ya, jadi kayak muncul rasa capek, capek minum obat lagi..obat lagi ,,”, (P5)

“....... Biasanye ibu selalu minum obat itu loh dek met..met apa'an ntuh namenye, suka lupa dah!! Hmm metformin, iya minum itu ibu. Tapi kadang ye bosan juga dek, pan ketemu obat terus.hahahaha ,,," (P6)

“........Kalau bapak rutin minum obat aja dek yang dikasih sama dokter, makanya bapak Alhamdulillah gk ada luka di kaki. Nih..nih..coba liat kaki bapak gk ada apa-apanya, gk ada luka.Tapi yaaa gitu dek kadang-kadang bapak suka lupa, untung ada anak yg biasa ingatin ,,," (P7)

“........Dijaga aja sih sus untuk minum obatnya yang dikasih dokter, selain itu juga ibu usaha minum daun-daun kayak daun afrika katanya bagus, terus ada juga daun-daun yang lain. Hmmm tapi rasanya pahit gk enak, tapi ya daripada kan ya kenapa-kenapa? Dipaksa aja walaupun enggak suka!!,,,", (P8) 
Saturasi data : dari delapan partisipan, semua menjawab tentang tantangan kepatuhan terapi yang dirasakan sebagai upaya pencegahan luka adalah: merasa males, bosan, capek, dan tidak suka dengan obat-obatan.

\section{Kemampuan Merawat Kaki yang Benar}

“.......Alas kaki juga nggak boleh pake yang jepit, jadi sendalnya yang lebar. Kalau pas mandi ibu sikat kaki pakai sikat bayi yang halus, terus di pakein sabun juga disikat bersih sela-selanya,," (P1)

“......Ibu teh kalau di rumah juga enggak lepas sendal pokoknya selalu pakai. Kata tetangga ibu mah gitu ngasih taunya, ibu kalau keluar kemana-mana harus pake sandal biar nggak luka cenah,, " (P2)

“.......Bapak setiap mandi selalu bersihkan kaki bapak, ya digosok sampe bersih jangan sampe ada yang kotor. Kalau misalkan luka juga langsung bapak obatin,," (P3)

“....Ibu di rumah biasa rendam pake air hangat campur garam, terus kalau di kamar mandi diurut pake handuk. Pernah juga saya rebus sereh terus saya pakein. Kalau ke pesta-pesta nggak pernah pake selop yang tinggi-tinggi, padahal dalam hati sebenarnya ibu juga mau bergaya-gaya kayak ibu yang laen. Tapi di pikir-pikir lagi ibu takut!! Jangan sampe dah kaki ibu buntung!!pokoknya sepatunya harus nyaman,," (P4)

“....... Kalau milih sepatu jangan sampai bikin lecet, harus milih yang empuk dan saya milih sepatu yang terbuka depannya supaya ada udara. Di tempat kerja udah izin juga sama bos, pake sepatu yang kebuka depannya. Kalau mandi saya pakekan sabun terus saya gosok-gosok ke ubin, kukunya di sikat pakai sikat gigi yang udah nggak kepake,," (P5)

“......Di rumah kalau mau potong kuku pas mandi di sabunin dulu banyak-banyak biar empuk, biar enak potong kukunye.Motongnye harus pake penjepit kuku, kagak boleh yang lain..." (P6)

“....Supaya ndak luka, bapak juga usahakan untuk jaga kaki bapak, kalau pas mau potong kuku sejak kecil saya punya kebiasaan potong kukunya sejajar jadi nggak terlalu dalem gitu sejajar sama dagingnya biar nggak luka,, " (P7)

“........Ibu kalau pagi-pagi gitu habis sholat subuh suka jalan-jalan depan rumah tapi pakai sendal, ya olahraga-olahraga juga gitu. Kalau sore mandi dulu kan ya, habis itu ibu olesi minyak tawon biar ada anget-angetnya,, "(P8)

Saturasi data: dari delapan partisipan, semua menjawab tentang bentuk perawatan kaki yang dilakukan yaitu dengan : memilih alas kaki yang tepat, memotong kuku ada tehniknya, selalu menggunakan sandal di dalam maupun di luar rumah, membersihkan kaki dengan menggunakan sikat halus dan merendam kaki dengan air hangat saat mandi. 


\section{PEMBAHASAN}

Dalam penelitian ini semua informan menyatakan persepsinya tentang pencegahan agar tidak terjadi luka diabetes yaitu diantaranya dengan menjaga diit. Diit yang dilakukan oleh para partisipan dilakukan dengan cara mengatur jumlah makanan, memilih jenis makanan yang sesuai serta mengatur jadwal makan. Menurut Black, Hawks (2014) diit yang tidak terkontrol bisa menyebabkan kadar glukosa dalam darah menjadi tinggi (hiperglikemia) sehingga menyebabkan akumulasi sorbitol di jaringan saraf. Hal ini menyebabkan akson dan dendrit tidak mendapat zat gizi dan serabut saraf tidak memiliki suplai darah tersendiri melainkan bergantung pada difusi zat gizi dan oksigen lintas membran. Ketika akson dan dendrit tidak mendapat zat gizi, saraf mentransmisikan impuls pelan-pelan dan selanjutnya mengurangi fungsi sensoris dan motoris. Ketika fungsi sensoris dan motoris menurun, maka pasien DM cenderung tidak menyadari bahwa dirinya mengalami cedera, karena sudah tidak merasakan apa-apa. Jika penurunan sensitivitas saraf tersebut terjadi pada bagian eksremitas bawah, maka akan memungkinkan untuk terjadinya luka pada kaki. Dari hasil wawancara mendalam diketahui bahwa sebagian besar partisipan mengatur jumlah makannya denga cara mengurangi porsinya, terutama porsi nasi.

Dalam penelitian lain yang pernah dilakukan oleh Trilestari (2016) yang menunjukan adanya hubungan bermakna antara perilaku diet dengan tingkat kadar gula dara sewaktu dengan nilai ( $\mathrm{p}<0,005)$. Disamping mengatur jumlah makanan, para partisipan juga berhatihati dalam memilih jenis makanan yang dikonsumsinya, karena pemilihan jenis makanan yang tidak tepat dapat menyebabkan ketidakseimbangan insulin dalam tubuh. Beberapa partisipan dalam penelitian ini memilih untuk mengganti makanan pokoknya dari beras putih menjadi beras merah. Berdasarkan penelitain lain yang dilakukan oleh Yonathan, Suhendra (2013) pada 30 orang responden di ketahui bahwa rerata kadar glukosa 2 jam post prandial pada orang setelah mengkonsumsi nasi merah adalah 101,77 $\mathrm{mg} / \mathrm{dL}$, berbeda sangat signifikan dengan setelah mengkonsumsi nasi putih sebesar 115,13 mg/dL.

Pencegahan lain yang dilakukan oleh partisipan agar tidak terjadi luka berdasarkan hasil wawancara mendalam adalah dengan rutin mengontrol kadar gula darah. Menurut Maryunani (2013) kadar glukosa yang meningkat dapat menyebabkan resiko terjadinya ulkus pada kaki dan sukar untuk disembuhkan. Hal ini disebabkan oleh penurunan kemampuan pembuluh darah dalam berkontraksi maupun relaksasi yang mengakibatkan perfusi jaringan bagian distal dari tungkai tidak baik. Kondisi ini juga merupakan lingkungan yang subur untuk berkembang biaknya kuman patogen yang bersifat anaerob karena plasma darah penderita diabetes yang tidak terkontrol baik dan memiliki kekentalan (viskositas) yang tinggi akibatnya aliran darah melambat dan suplai oksigen berkurang.

Menurut Soewondo (2015) untuk bisa menyatakan bahwa kadar glukosa darah terkendali, tentunya tidak dapat bergantung pada hilangnya gejala diabetes mellitus saja tetapi harus dengan pemeriksaan kadar glukosa darah. Pemantauan kadar glukosa darah tersebut dapat dilakukan di laboraturium, di klinik saat konsultasi, ataupun dapat dilakukan sendiri oleh penyandang DM di rumah. Dari hasil wawancara mendalam, partisipan dalam penelitian ini memiliki cara yang beragam dalam melakukan kontrol gula darah. Beberapa partisipan ada yang melakukan kontrol gula darah di pelayanan kesehatan. Dari sinilah kita sebagai seorang perawat sudah seharusnya menjalankan peran sebagai edukator yang memberikan informasi serta mendidik penderita diabetes agar melakukan monitoring kadar gula darah secara teratur. Peranan perawat haruslah benar-benar dilakukan agar dapat 
menekan angka biaya perawatan kaki dan amputasi akibat ulkus (Kusnanto, 2004). Selain itu ada beberapa partisipan dalam penelitian ini yang melakukan kontrol gula darahnya secara mandiri di rumah. Monitoring gula darah secara mandiri atau self monitoring blood glucose merupakan sebuah metode modern yang di terapkan pada penyandang diabetes mellitus (IDF, 2009). Dengan metode tersebut diharapkan mampu mengurangi komplikasikomplikasi akibat diabetes yang dapat berefek kepada pembiayaan yang memberatkan penyandang diabetes mellitus. Hal ini sesuai dengan data yang di himpun dari WHO yang menyatakan bahwa pada tahun 2013 salah satu beban pengeluaran terbesar dunia adalah diabetes mellitus yaitu sekitar 612 miliar dollar (WHO, 2016). Gula darah yang tinggi dapat memicu terjadinya neuropati diabetik, penyandang diabetes memiliki resiko 11 kali lipat untuk mengalami neuropati dibanding yang tidak menderita (Suri et al, 2016). Hasil penelitian yang dilakukan oleh Kiki (2017) yang menyatakan bahwa ada perbedaan sensitivitas sebelum dan sesudah responden melakukan self monitoring blood glucose. Disamping itu perlu adanya dukungan dari keluarga untuk memberikan dorongan atau semangat kepada penyandang diabetes agar rutin melakukan kontrol gula darah. Hal ini sejalan dengan penelitian dari Wibisono (2012), menyatakan bahwa dukungan dari keluarga dan motivasi internal merupakan faktor pendorong kontrol glukosa darah serta membantu penerimaan klien terhadap kondisinya.

Patuh dalam prosedur pengobatan merupan kunci lain dari partisipan dalam menghindarkan diri dari luka diabetik. Hal ini di dasari dari pengalaman para responden selama proses penelitian. Kepatuhan terhadap terapi baik insulin maupun OHO sangat diperlukan, karena menurut Damayanti (2015) terapi insulin menjaga kadar gula darah normal atau mendekati normal. Pada DM tipe 2, insulin terkadang diperlukan sebagai terapi jangka panjang untuk mengendalikan kadar glukosa darah jika dengan diet, latihan fisik dan Obat Hipoglikemia Oral (OHO) tidak dapat menjaga gula darah dalam rentang normal. Hal ini sejalan dengan penelitian yang dilakukan oleh Salystianingsih, dkk (2011) diperoleh hasil bahwa ada hubungan yang signifikan antara tingkat kepatuhan untuk mengambil $\mathrm{OHO}$ dan glucose contens darah pada pasien DM tipe 2.

Kemampuan merawat kaki yang benar menjadi salah satu hal yang penting untuk dilakukan. Hal ini didasari pada hasil wawancara mendalam yang dilakukan pada responden yang mengungkapkan pengalamnnya dalam menjaga dan merawat kaki diantaranya yaitu teliti dalam memilih alas kaki. Pada penelitian lain juga mengatakan bahwa terdapat hubungan kebermaknaan antara pemilihan alas kaki diabetes di buktikan dengan nilai probabilitas $\leq 0,05$ dari hasil uji statistiknya (Dewi.A. 2007). Disamping teliti dalam memilih alas kaki, para responden juga memotong kuku dengan hati-hati. Pemotongan kuku yang terlalu pendek akan melukai kulit disekelilingnya, pertumbuhan kuku ke dalam jaringan mengakibatkan luka infeksi pada jaringan di sekitar kuku. Keadaan ini di sebabkan oleh perawatan kuku yang tidak tepat salah satunya kebiasaan mencungkil kuku yang kotor. Kuku juga merupakan sumber kuman, jadi bila ada luka akan mudah terinfeksi, yang ditandai dengan sakit pada jaringan disekitar kuku, merah, bengkak, dan keluar cairan nanah (Dewi, A. 2007). 


\section{SIMPULAN}

Jenis penelitian kualitatif dengan menggunakan desain fenomenologi deskriptif yang menghasilkan 8 (delapan) informan sebagai sumber data yang diperoleh selama penelitian dilapangan. Dari hasil wawancara dengan informan didapat 4 (empat) tema. Berdasarkan hasil analisis peneliti sudah mendapatkan saturasi data. Penelitian ini sudah menjawab tujuan penelitian yaitu mengeksplorasi pengalaman pengalaman pasien diabetes melitus tipe 2 dalam melakukan tindakan pencegahan terjadinya luka di PERSADIA Rumah Sakit Islam Jakarta Pondok Kopi.

Hasil penelitian ini mengindentifikasi 4 (empat) tema yaitu :

(1) Menjaga diit, seperti :mengatur jumlah makanan, memilih jenis makanan yang sesuai serta mengatur jadwal makan. (2) Aktivitas kontrol gula darah yang beragam, seperti : mengontrol gula darah secara mandiri dengan menggunakan alat sendiri dan kontrol gula darah di pelayanan kesehatan. (3) Tantangan kepatuhan terapi, seperti : bosan, capek, dan alergi terhadap obat farmakologis. (4) Kemampuan merawat kaki yang benar, seperti : teliti dalam memilih alas kaki, mencuci kaki dengan menggunakan air rebusan sereh, membersihkan kaki dengan sikat halus dan memotong kuku dengan tehnik yang benar.

Pengalaman pasien diabetes mellitus tipe 2 dalam mencegah terjadinya luka, mengungkapkan bahwa untuk mencegah terjadinya luka diperlukan kesabaran dalam menjalani semua prosedur terapi, karena selama proses pengobatan tersebut sering kali partisipan mengalami beberapa tantangan. Tantangan itu diantaranya bosan, merasakan capek maupun alergi terhadap obat-obatan farmakologis. Walaupun demikian para partisipan harus melawan tantangan tersebut agar bisa terhindar dari komplikasi luka diabetes yang sering terjadi.

Hal penting yang peneliti dapat simpulkan dalam penelitian ini bahwa cara pencegahan terjadinya luka yang dilakukan oleh pasien diabetes mellitus tipe 2 adalah dengan menjaga diit sesuai aturan, patuh dalam menjalani prosedur terapi dan rutin melakukan control gula darah Disamping itu dukungan dari keluarga dan motivasi internal merupakan faktor penting yang mendorong klien untuk untuk melakukan kontrol gula darah, serta membantu klien dalam menerima kondisinya.

\section{SARAN}

Direkomendasikan kepada pihak-pihak yang terkait dengan pencegahan terjadinya luka diabetes adalah:

Pelayanan keperawatan tingkat puskesmas harus menjadi konselor dan perlu mengadakan program edukasi mengenai perawatan kaki pada pasien DM tipe 2, berupa penyuluhan maupun pemberian leaflet yang berisi tentang pencegahan agar tidak terjadi luka. Perawat juga harus dibekali dengan pengetahuan yang benar tentang upaya pencegahan terjadinya luka sehingga kedepannya diharapkan mampu melakukan pengkajian kaki secara mandiri terhadap pasien-pasien yang beresiko terjadi luka.

Untuk pasien diabetes mellitus tipe 2 sebaiknya harus sering mengumpulkan informasi-informasi dari media cetak maupun elektronik terkait pencegahan agar tidak terjadi luka pada kaki.Penyandang diabetes mellitus juga diharapkan mampu berperan aktif dalam sosialisasi dengan penyandang diabetes lainnya dalam mendiskusikan tindakan yang tepat agar terhindar dari resiko terjadinya luka. 
Untuk peneliti selanjutnya disarankan perlu mengadakan penelitian yang lebih mendalam lagi tentang pengalaman pasien diabetes mellitus tipe 2 dengan waktu menderita DM lebih lama. Hal ini menjadi penting, karena lebih menunjukan akan kebutuhan informasi dan edukasi mengenai pencegahan terjadinya luka. Disarankan bagi untuk penelitian selanjutnya sebaiknya menggunakan pendekatan grounded theory yang lebih refleksif dan terbuka.

\section{DAFTAR PUSTAKA}

ADA (American Diabetes Association). (2016). Statistics about Diabetes. http://www.diabetes-basic/statistic/ Diunduh pada tanggal 06 Februari 2018

Arianti. (2012). Hubungan Perawatan Kaki dengan Resiko Ulkus Kaki Diabetes di Rumah Sakit PKU Muhammadiyah Yogyakarta. Diunduh pada tanggal 07 Februari 2018

Black, M. J \& Hawks, H. J., (2014). Keperawatan Medikal Bedah. Edisi 8. Jakarta: CV. Pentasada Media Edukasi

Damayanti, S. (2015). Diabetes Mellitus \& Penatalaksanaan Keperawatan. Yogyakarta: Nuha Medika

Dewi, A. (2007). Hubungan Aspek-Aspek Perawatan Kaki Diabetes dengan Kejadian Ulkus Kaki Diabetes pada Pasien Diabetes Mellitus. https:media.neliti.com. Di unduh tanggal 09 Maret 2018

International Diabetes Federation (IDF). (2009). Self Monitoring of Blood Glucose in Non Insulin Treated Type 2 Diabetes. Australia: University of Sydney. Diunduh pada tanggal 26 Juni 2018 dari http://www.idf.org

International Diabetes Federation (IDF). (2009). Diabetes Atlas, International Diabetic Federation, $4^{\text {th }}$ edition. Diunduh pada tanggal 06 Februari 2018 dari http://www.diabetesatlas.org/

International Diabetes Federation (IDF). (2015). IDF Diabetes Atlas. Seven Edition. www.oedg.at/pdf/1606_IDF_Atlas_2015_UK.pdf. Diunduh pada tanggal 06 Februari 2018

Kiki, R. A. (2017). Self-Monitoring of Blood Glucose dalam Mencegah Neuropati pada Eksremitas Bawah Pasien Diabetes Mellitus Tipe II. https://jurnal.umj.ac.id. Diunduh pada tanggal 10 Maret 2018

Kumar V, Abbas K \& Aster C. (2015). Buku Ajar Patologi Robbins. Edisi 9. Alih bahasa oleh Nasar \& Cornain. Singapura: Elsevier Inc

Kusnanto. (2004). Pengantar dan Profesi Praktik Keperawatan Profesional. Jakarta: EGC

LeMone., Burke, \& Bauldoff. (2016). Keperawatan Medikal Bedah, Alih bahasa. Jakarta: EGC

Maghfuri, A. (2016). Buku Pintar Perawatan Luka Diabetes Melitus. Jakarta: Penerbit Salemba Medika

Maryunani, A. (2013). Step by Step Luka Diabetes dengan Metode Perawatan Luka Modern. Bogor: In Media

Moya, J. M. (2004). Manajemen Luka. Jakarta: EGC

Potter, P.A., Perry, A.G. (2005). Buku Ajar Fundamental Keperawatan: Konsep, Proses, dan Praktik. Edisi 4. Volume 1. Alih Bahasa : Yasmin Asih, dkk. Jakarta: EGC

Rosdahl, C. B., \& Kowalski, M. T. (2014). Buku Ajar Keperawatan Dasar. Edisi 10. Jakarta: EGC 
Salystianingsih.W. (2011). Hubungan Tingkat Kepatuhan Minum Obat Hipoglikemik Oral dengan Kadar Glukosa Darah pada Pasien Diabetes Mellitus Tipe 2. https://journal.ugm.ac.id. Diunduh pada tanggal 20 Maret 2018

Smeltzer, S, \& Bare. (2008). Brunner \& Suddarths Textbook of Medical Surgical Nursing. Philadelpia: Lippin cott

Soegondo, S. (2015). Penatalaksanaan Diabetes Mellitus Terpadu. Jakarta: Balai Penerbit FKUI

Soewondo. P. (2015). Penatalaksanaan Diabetes Mellitus Terpadu. Jakarta: Balai Penerbit FKUI

Suri, M. H., Haddani, H., \& Sinulingga, S. (2016). Hubungan Karakteristik, Hiperglikemi, dan Kerusakan Saraf Pasien Neuropati Diabetik di RSMH. https:/lejournal. unsri.ac.id /index. php/jkk/article/view/2838 Diunduh pada tanggal 24 juni 2018

Suriadi. (2004). Perawatan Luka Edisi I. Jakarta: CV. Sagung Seto

Trilestari. H. (2016). Hubungan Perilaku Diet dengan Kadar Gula Darah Sewaktu pada Penderita Diabetes Mellitus Tipe II di Ambarketawang Yogyakarta. Di unduh pada tanggal 08 Agustus 2018 dari digilib.unisayogya.ac.id

Wibisono, A. H. (2012). Pengalaman Pasien DM Dalam Mengontrol Gula Darah Secara Mandiri. Tesis. Jakarta. FIK: UI

World Health Organization (WHO). (2015). Standards of Medical Care in Diabetes. care.diabetesjournals.org/content/diacare/suppl/2016/12/15/...DC_40_S1_final.pdf/. Diunduh tanggal 07 Februari 2018

World Health Organization. (2016). Global Status Report on Noncommunicable Diseases 2010. Description of the Global Burden of NCDs, Their Risk Factors and Determinants. 2011. Google Scholar

Yonathan. C., \& Suhendra.A. (2013). Perbandingan Pengaruh Nasi Putih dengan Nasi Merah terhadap Kadar Glukosa Darah. Jurnal Jurusa. 2013-repository.unhas.ac.id. Diunduh tanggal 07 Februari 2018 